\title{
Bayesian inference for predicting ecological water quality under different climate change scenarios
}

\author{
J. Kotta, R. Aps \& H. Orav-Kotta \\ Estonian Marine Institute, University of Tartu, Estonia
}

\begin{abstract}
The aim of this paper is to assess the separate and interactive effects of eutrophication and climate variables on the sea water quality in Pärnu Bay (the Gulf of Riga, Baltic Sea) using multivariate statistical analyses and the Bayesian Belief Network (BBN) methodology. The assessment was based on the following biological quality elements: phytoplankton, submerged aquatic vegetation and benthic invertebrates. The multivariate statistical analyses suggest that zoobenthos communities are largely driven by weather conditions (i.e. climate variables), phytoplankton by nutrient loads while the dynamics of macrophyte communities was due to the combined effect of weather and nutrient loads. The BBN constructed for this study represents uncertainty in ecological water quality assessment. Probabilistic modeling shows that phytoplankton and zoobenthos are not sensitive to climate change impacts while phytobenthos would suffer from decrease in sea water salinity. Under climate change, therefore, phytobenthos is one of the key variables in determining the water quality in the study area.
\end{abstract}

Keywords: Baltic Sea, Bayesian inference, climate change, eutrophication, water quality assessment.

\section{Introduction}

Eutrophication and climate change are severely threatening coastal marine environments worldwide leading to loss of biodiversity and concerns about the potential for dramatic changes in ecosystem structure and functioning [1-3]. Eutrophication events are often associated to algal blooms, accumulation of organic matter and development of anoxia $[4,5]$. Shifts in climatic conditions are 
known to alter the patterns of distribution, abundance and diversity of species $[6,7]$. It is currently believed that climate variables define broad patterns of distribution and are the significant factors in community variability. Within these patterns, smaller-scale processes like nutrient loading operate at a lower intensity to modify distributions $[8,9]$.

Thus, given that different natural and anthropogenic processes do not act in isolation, changes in the structure of ecosystems are likely driven by changes between the complex interrelationships of climate and eutrophication variables and ecosystem elements $[6,7,10,11]$. There is currently a critical knowledge gap in how eutrophication and climate variables interactively impact the dynamics of different ecosystem elements. It is essential though, that we improve our understanding of how the influence of one may modify the action of others and thereby determine their combined or interactive effects. The response of any given species to eutrophication and climate variables is unique, as some species are relatively resistant to change, whereas others are more sensitive. Nevertheless, if the influence of climate variables transfers down the hierarchy, then climate variability should result in larger responses to population dynamics than eutrophication variables. Alternatively, eutrophication and climate variables may interfere with the communities at similar intensities, therefore speciesspecific responses determine if separate or interactive effects prevail. In order to validate either prediction, we need to establish the links between environmental fluctuations and the temporal dynamics of species within a community.

The EU Water Framework Directive is a Community legislative instrument in the field of environment protection that establishes a common framework for keeping water quality at favorable level. To implement the directive, classification systems need to be established that allow us to assign each waterbody one of five ecological quality classes. This classification system has to be developed using mainly biological indicators (Water Quality Elements). Relevant indicators have to be developed and intercalibrated to be useable in the classification system [12]. The choice of indicators and assessment method depends on the spatial and temporal patterns of the pressures and communities involved. To date, the most assessment schemes involved eutrophication variables but left us ignorant of how and at which extent climate change contributed to the ecological water quality. Without such knowledge, however, the classification scheme is inefficient and has low predictive power in our rapidly changing environment.

The aim of this study is to quantify the separate and combined impacts of nutrient loading, temperature, salinity, and wind conditions on phytoplankton, submerged aquatic vegetation, and benthic invertebrates inhabiting a brackish water ecosystem. Issue is exemplified by scenario based sea water quality probabilistic modeling for Pärnu Bay (the Gulf of Riga, Baltic Sea) assessing how the choice of different load and climate change scenarios cascades up to the ecological water quality of the sea area. 


\section{Material and methods}

The Gulf of Riga is a wide, shallow, semi-enclosed brackish water ecosystem of the Baltic Sea (Figure 1). The Gulf receives freshwater from a large drainage area $\left(134,000 \mathrm{~km}^{2}\right)$, primarily entering the southern part of the basin. The average salinity varies from $0.5-2.0 \mathrm{psu}$ in surface layers in its southern and northeastern areas to $7 \mathrm{psu}$ at the straits. In most parts, however, the salinity is 5.0-6.5 psu with the absence of a permanent halocline. Due to its shallowness, the dynamics of both surface and deep water temperatures are directly coupled with air temperatures. The oxygen regime is relatively good due to strong vertical mixing. In most areas, oxygen concentrations are higher than $5 \mathrm{ml} \mathrm{l}^{-1}$ [13]. In consequence of limited water exchange, the Gulf is more eutrophicated than the Baltic Proper, and the outflow of nutrients through the straits is higher than the inflow $[14,15]$.

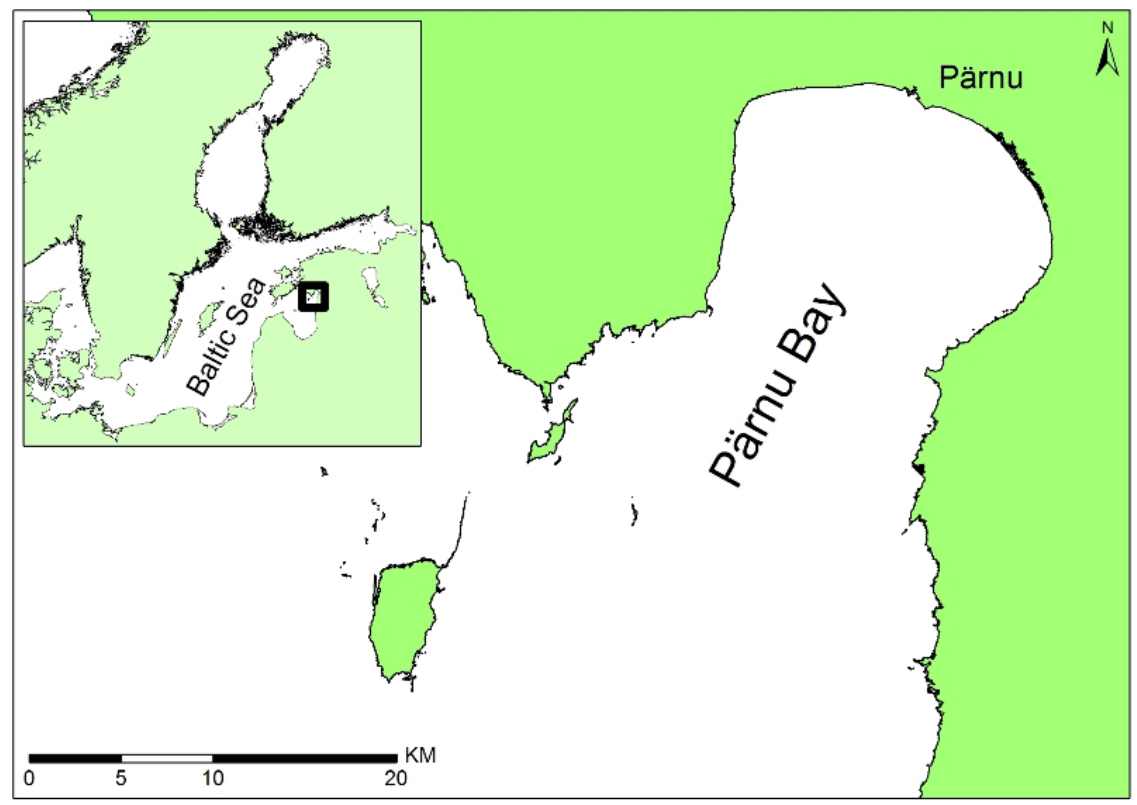

Figure 1: $\quad$ Pärnu Bay sea area (the northeastern Gulf of Riga, Baltic Sea).

The riverine loading is the most important pathway of nutrients into the Gulf of Riga and exceeds the combined contribution from atmospheric deposition, point emission from cities and industries along the coast, and nitrogen fixation by marine organisms [16]. Higher concentrations of nutrients are found in the southern and northeastern parts of the Gulf, i.e. adjacent to the mouths of larger rivers. Beside spatial variation, the concentration of nutrients has a strong component of seasonal variation. Strong vertical mixing processes in autumn and winter result in a high nutrient content in the upper layer during January and 
February. Both dissolved inorganic nitrogen and phosphate pools of the upper mixed layer are exhausted by mid-May, except at river mouths where nutrient concentrations decline only in July. In summer and early autumn, the concentrations remain low. After November, a gradual increase takes place due to the higher intensity of vertical mixing [13].

Despite its extensive sublittoral areas, the Gulf of Riga is characterized by low phytobenthic diversity. The whole system relies on plankton primary production [17]. Succession of phytoplankton starts at the end of March and ends in the first half of June. Summer succession starts in the middle of June and ends in the middle of September [18]. Due to low salinity and uniformity of habitat, the number of benthic invertebrate species is low. However, those that inhabit the area have formed strong populations, where crustaceans, oligochaetes and polychaetes are most abundant and burrowing bivalves have the highest biomass among invertebrate communities [19, 20].

Estonian water quality classification system for surface waters is based on type specific reference conditions and fulfills the requirements of WFD. The established classification system includes biological and supporting physicochemical quality elements. Biological quality elements are species composition, abundance and biomass of phytoplankton, benthic macrovegetation, and benthic macroinvertebrates. Physico-chemical quality elements supporting biological elements are water transparency, temperature conditions, oxygen concentration, salinity, and nutrient concentration.

In Pärnu Bay (the northeastern Gulf of Riga) water $C h l \alpha$, the biomass share of perennial macroalgae and Zoobenthos Community Index (ZKI) are commonly used ecological indicators for eutrophication under the Water Framework Directive assessment scheme. $C h l \alpha$ is used as a proxy for phytoplankton biomasses and it is divided into 5 classes: high (0-3.5), good (3.6-4.4), moderate (4.5-9.0), poor (9.1-13.5) and bad (>13.6). The macrophyte indicator is calculated as the coverage of species and it is divided into the quality classes as follows: high (share of perennial macroalgae 49-100\%), good (30-48\%), moderate (18-29\%), poor (6-17\%) and bad (0-5\%). The ZKI index divides benthic invertebrates into three distinguished groups according to their sensitivity to an increasing stress (including eutrophication). The index also acknowledges that the increasing nutrient loads increase benthic biomass to a certain extent and above this threshold level drops suddenly. The class boundaries of ZKI are as follows: high (0.80-1.00), good (0.50-0.79), moderate (0.30-0.49), poor $(0.10-0.29)$ and bad (0-0.09). In the Estonian WFD classification system, the general status of the water area follows the "one out all out" rule. According to this principle, the state of the area under consideration is determined by the biological quality elements classified to be in the worst state. Thus, in a case that one variable is in "Poor" status and the others are classified as "Good", the general status of the area will still be "Poor".

Phytoplankton sampling was conducted bimonthly and macrophyte and benthic invertebrate samples annually in 1991-2006. A thorough description of sampling approaches and techniques is given in [21, 22]. Multivariate data analyses were performed by the statistical program "PRIMER" version 6.1.5 
[23]. BEST analysis (BIOENV procedure) was used to relate eutrophication and climate variables to the biological quality elements. This analysis shows which environmental variables best predict the observed values of quality elements. Environmental variables were normalized prior to analyses. A Spearman rank correlation (Rho) was computed between the similarity matrices of abiotic environment (Euclidean distance) and different quality elements (a zero-adjusted Bray Curtis distance). A global BEST match permutation test was run to examine the statistical significance of observed relationships between environmental variables and biotic patterns.

The outcomes of statistical analyses were converted to prior probabilities taking into account the plausible scenarios of eutrophication and climate change. Projected changes in wind in the northern Baltic Sea differ widely between various climate models. It is expected though that the mean daily wind speed over sea areas would increase up to $18 \%$ in winter. Oceanographic studies also show that changes in temperature would be 4 to $6^{\circ} \mathrm{C}$ in winter and 3 to $5^{\circ} \mathrm{C}$ in summer. Such shifts in temperature may have no pronounced direct effect on biological quality elements considering the large natural temperature fluctuation of the Baltic Sea basin. However, the increase in temperature significantly affects ice conditions reducing the ice extent by some 50 to $80 \%$ and therefore indirectly amplifying the effects of wind conditions. Finally, the average salinity of the Baltic Sea is projected to decrease between 8 and $50 \%$ of the recent level [24]. In our paper we used three independent climate change scenarios: (1) the current situation, (2) $50 \%$ of the potential consequences of climate change and (3) the most severe consequences of climate change. We used two independent nutrient loading scenarios for Estonia: (1) the current situation and (2) the intensified agriculture representing approximately $40 \%$ increase in total $\mathrm{N}$ loading whereas the decrease in phosphorus load is not expected due to improvements in manure handling. Climate change and eutrophication driven scenarios for the Pärnu Bay waterbody are summarized in Table 1.

Bayesian Belief Network (BBN) was constructed with an aim to calculate the probability of different quality states of the waterbody using the HUGIN RESEARCER software.

Table 1: Summary of scenarios used for the probabilistic modeling of water quality in Pärnu Bay (the northeastern Gulf of Riga, Baltic Sea).

\begin{tabular}{|l|l|l|}
\hline Scenario & Climate & Eutrophication \\
\hline $\mathbf{1}$ & Current & Current \\
\hline $\mathbf{2}$ & Current & Elevated \\
\hline $\mathbf{3}$ & $50 \%$ change & Current \\
\hline $\mathbf{4}$ & $50 \%$ change & Elevated \\
\hline $\mathbf{5}$ & $100 \%$ change & Current \\
\hline $\mathbf{6}$ & $100 \%$ change & Elevated \\
\hline
\end{tabular}




\section{Results and discussion}

Chl $\alpha$ was related to both eutrophication (P load) and climate (southerly winds) variables. However, eutrophication variable had stronger effects than climate variable, and the models that combined both climate and eutrophication variables did not explain additional variation compared to the separate model of eutrophication variables. The models described $59 \%$ of the variability of data. As our scenarios did not predict the changes in phosphorus loading then the effects of eutrophication and climate change on phytoplankton were moderate.

The share of perennial macrophytes was related to both eutrophication ( $\mathrm{N}$ load) and climate variables (salinity). The models that combined both climate and eutrophication variables explained additional variation in phytobenthos data compared to the separate models of climate and eutrophication. The models described $90 \%$ of the variability of data. Macrophytes were particularly sensitive to the climate induced reduction in salinity. Benthic macrophytes disappeared under low salinity level and the index did not capture anymore the dynamics of nutrient loading. The prevailing perennial macrophytes of the northeastern coasts of the Gulf of Riga inhabit at lower salinity tolerance limits and even small reduction in salinity is expected to induce the mass mortality of the species [25].

Benthic invertebrates were related to both eutrophication ( $\mathrm{N}$ load) and climate variables (southerly winds). However, climate variables had stronger effects than eutrophication variables, and the models that combined both climate and eutrophication variables did not explain additional variation compared to the separate model of climate variables. The models described $46 \%$ of the variability of data. The finding that benthic invertebrate communities were better explained by climate variables than eutrophication variables was somewhat unexpected. There exists a wealth of literature demonstrating the strong link between eutrophication and benthic invertebrate communities in the study area $[20,21$, $26,27]$. However, all of these studies did not include climate variables in their analyses. In fact, our data shows a link between climate and load data (e.g. linear regression analysis between the North Atlantic Oscillation index and $\mathrm{N}$ loads: $r^{2}=0.14, p<0.001$ ), which may partly explain the observed patterns of earlier studies. Alternatively, our benthic invertebrate time series coincides with large variability in temperature and wind conditions and does not cover the periods when the loads were substantially higher (e.g. in the 1980s). Earlier studies, in contrast, included invertebrate data collected once a decade and therefore covered a larger time span (e.g. from the late 1950s to early 2000s) and thus larger variability in nutrient loads.

A simple BBN was constructed with an aim to calculate the probability distribution over different states of water quality in Pärnu Bay (Figure 2).

This BBN network contains information variable "SCENARIO", that is representing the set of scenarios developed for probabilistic modeling. A hypothesis variable "WATER_QUALITY" is representing the probability distribution over different states of water quality in relation to "SCENARIO" and "INDICATOR" chosen. The information from information variable propagates through the links of the network to update the probability distribution over the 


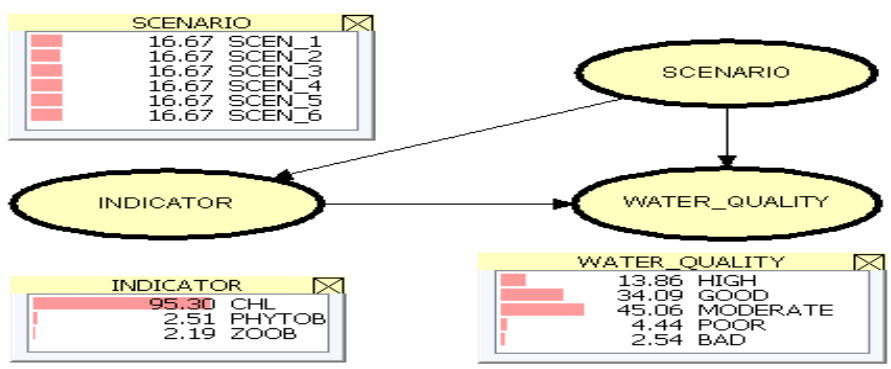

Figure 2: Probability distribution of different states of water quality in Pärnu Bay (total ignorance: no information on scenario realization).

hypothesis variable. The causal structure of the network therefore encapsulates the reasoning process that is employed to reason about the likelihood of any hypothesis state given the current state of the information variables.

The problem of converting a state of knowledge to a prior probability assignment is a problem that lies at the heart of Bayesian probability theory. Assessment of the water quality states is largely based on the analysis of "INDICATOR" variables (Chl $\alpha$, phytobenthos, and zoobenthos) presented above in this chapter.

Our knowledge may easily be not enough to determine which particular alternative "SCENARIO" will materialise and therefore this knowledge shall be associated with our current uncertainty. If our current state of knowledge on scenario materialization is total ignorance then we will not be able to distinguish between various alternatives and this leads to the uniform probability distribution over "SCENARIO" set as presented in Figure 2. However, we can see the dominant role of $\mathrm{Chl} \alpha(95.30 \%)$ in determining the water quality, and the probability distribution over the quality states is $47.95 \%$ for " $H I G H$ " to "GOOD" and $52.05 \%$ for "MODERATE" to "BAD".

If we have, for example, the "SCENARIO 1" materialized with the $C h l \alpha$ as indicator variable (Figure 3), then the probability distribution over the sea water quality states is $44 \%$ for "HIGH" to "GOOD" and $56 \%$ for "MODERATE" to "BAD".

Similar results in relation to the $C h l \alpha$ are obtained for all 6 scenarios. At the same time, in a case of "SCENARIO I" and with phytobentos taken as an indicator variable (Figure 4) the probability distribution over the water quality states is $55.44 \%$ for "HIGH" to "GOOD" and $44.56 \%$ for "MODERATE" to "BAD". Similar results are obtained also for "SCENARIO 2".

However, "PHYTOBENTOS" as an indicator variable is associated with the "BAD" water quality state in a case of "SCENARIO 3" to "SCENARIO 6" with probability of $96 \%$ (Figure 5). As it was concluded above the macrophytes are particularly sensitive to the climate change caused reduction in salinity that would induce the mass mortality of perennial macrophytes in Pärnu Bay.

Furthermore, if we have, for example, the "SCENARIO 1" materialized with the "ZOOBENTHOS" as an indicator variable (Figure 6), then the probability 


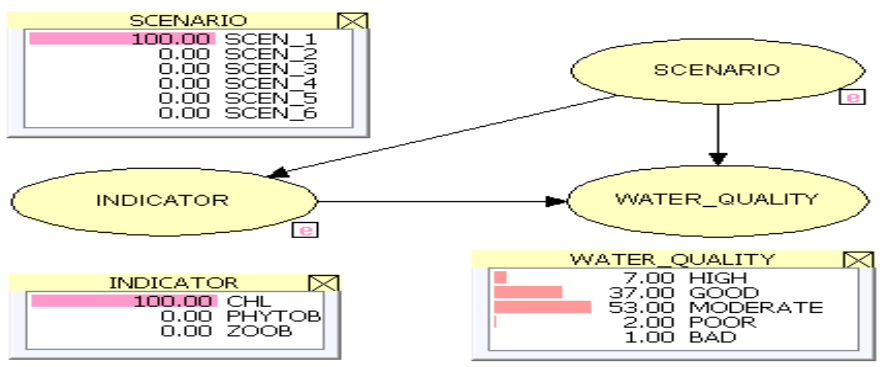

Figure 3: Probability distribution of different states of water quality in Pärnu Bay (scenario 1, Chl $\alpha$ as an indicator variable)

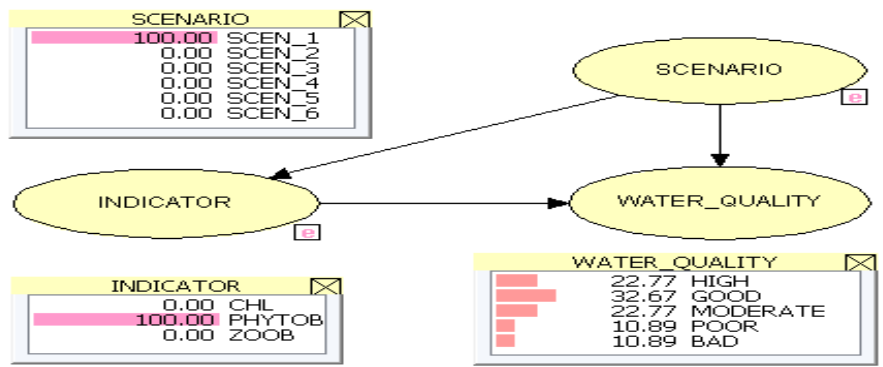

Figure 4: Probability distribution of different states of water quality in Pärnu Bay (scenario 1, phytobenthos as an indicator variable).

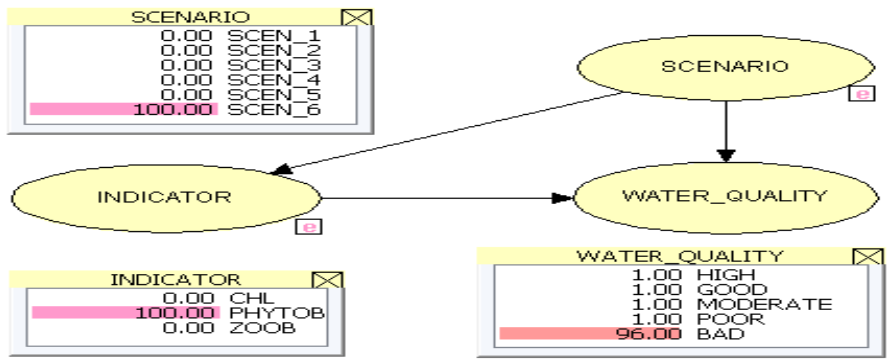

Figure 5: Probability distribution of different states of water quality in Pärnu Bay (scenario 6, phytobenthos as an indicator variable).

distribution over the sea water quality states is $89.94 \%$ for " $H I G H$ " to " $G O O D$ " and $10.06 \%$ for "MODERATE" to "BAD" while for most severe "SCENARIO 6" (Figure 7) the corresponding probabilities are $92 \%$ and $8 \%$. 


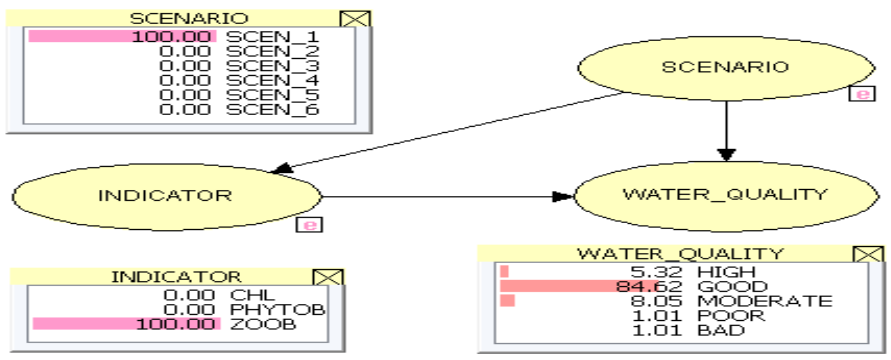

Figure 6: Probability distribution of different states of water quality in Pärnu Bay (scenario 1, zoobenthos as an indicator variable).

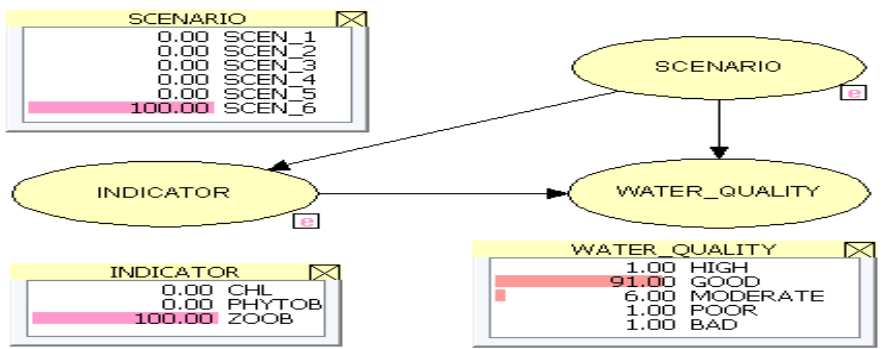

Figure 7: Probability distribution of different states of water quality in Pärnu Bay (scenario 6, zoobenthos as an indicator variable).

Based on the scenario modeling it is possible to conclude that "ZOOBENTHOS" as an indicator variable is representing the most stable element of the assessment scheme in the study area.

Important advantages of Bayesian inference in assessing the potential impact of the different eutrophication and climate change related drivers (nutrient loading, temperature, salinity, and wind conditions) on phytoplankton, submerged aquatic vegetation, and benthic invertebrates that inhabit a brackish water ecosystem do not mean that the results are the sole determinants of possible management decisions. Legal mandates and political, social, and economic considerations may lead managers to make decisions that are more or less protective. Reducing risk of the bad ecological water quality to the lowest level may be too expensive or not technically feasible. Thus, although Bayesian inference based sea water quality assessments provide critical information to politicians and managers; they are only part of the wider environmental decisionmaking process.

Probabilistic modeling shows clearly the magnitude of uncertainty related to the sea water quality assessments. Academic science can, at its best, inform the policy on the relative probability of an environmental threats but science cannot 
set political priorities telling us how we should allocate our social and financial resources to meet these threats [28]. Advising on mitigation measures related to the potential impacts of climate change is rather a task for the regulatory science that is expected to generate information needed to meet regulatory requirements and to provide reliable information for decision makers. The role of uncertainty is also different: predictive certainty of regulatory science is required by the political process and by legal requirements, while uncertainty is expected and "embraced" by academic science [29].

\section{Conclusions}

Probabilistic Bayesian modeling revealed considerable uncertainty related to the sea water quality assessments that should be taken into account when planning mitigation measures related to the potential impacts of climate change.

Modeling results show that phytoplankton and zoobenthos are not sensitive to the expected impacts of climate change while phytobenthos would suffer from decrease in sea water salinity. Under climate change, therefore, phytobenthos is one of the key variables in determining the water quality in the study area.

\section{Acknowledgements}

The study was supported by the Baltic Sea Region Programme 2007-2013 project BaltSeaPlan: Introducing Maritime Spatial Planning in the Baltic Sea, by the Estonian target financing programs SF0180104s08, SF0180013s08, and by the Estonian Science Foundation grants 6015, 7813.

\section{References}

[1] McGowan, J.A., Cayan, D.R., Dorman, L.M. Climate-ocean variability and ecosystem response in the northeast Pacific. Science, 281, pp. 210217, 1998.

[2] Howarth, R.W., Swaney, D.P., Butler, T.J., Marino, R., Climatic control on eutrophication of the Hudson River Estuary. Ecosystems, 3, pp. 210$215,2000$.

[3] Jackson, J.B.C., Kirby, M.X., Berger, W.H., Bjorndal, K.A., Botsford, L.W., Bourque, B.J., Bradbury, R.H., Cooke, R., Erlandson, J., Estes, J.A., Hughes, T.P., Kidwell, S., Lange, C.B., Lenihan, H.S., Pandolfi, J.M., Peterson, C.H., Steneck, R.S., Tegner, M.J., Warner, R.R. Historical overfishing and the recent collapse of coastal ecosystems. Science, 293, pp. 629-637, 2001.

[4] Paerl, H.W. Assessing and managing nutrient-enhanced eutrophication in estuarine and coastal waters: Interactive effects of human and climatic perturbations. Ecological Engineering, 26, pp. 40-54, 2006. 
[5] Andersen, J.H., Schlüter, L., Ærtebjerg, G. Coastal eutrophication: recent developments in definitions and implications for monitoring strategies. Journal of Plankton Research, 28, pp. 621-628, 2006.

[6] Hughes, L. Biological consequences of global warming: is the signal already apparent? Trends in Ecology and Evolution, 15, pp. 56-61, 2000.

[7] Lotze, H.K., Lenihan, H.S., Bourque, B.J., Bradbury, R.H., Cooke, R.G., Kay, M.C., Kidwell, S.M. Depletion, degradation, and recovery potential of estuaries and coastal seas. Science, 312, pp. 1806-1809, 2006.

[8] Barry, J.P., Dayton, P.K. Physical heterogeneity and the organization of marine communities. In: J. Kolasa, S.T.A. Pickett (Eds), Ecological heterogeneity. Springer-Verlag, New York, pp. 270-320, 1991.

[9] Steele, J.H., Henderson, E.W. Coupling between physical and biological scales. Philosophical transactions of the Royal Society of London, (B) 343, pp. 5-9, 1994.

[10] Grall, J., Chauvaud, L. Marine eutrophication and benthos: the need for new approaches and concepts. Global Change Biology, 8, pp. 813-830, 2002.

[11] Stenseth, N.C., Mysterud, A., Ottersen, G., Hurrell, J.W., Chan, K.-S., Lima, M. Ecological effects of climate fluctuations. Science, 297, pp. 1292-1296, 2002.

[12] EC. Directive 2000/60/EC of the European Parliament and of the Council of 23 October 2000 establishing a framework for Community action in the field of water policy. Legislative acts and other instruments. ENV221 CODEC 513. European Union, 2000.

[13] Kotta, J., Lauringson, V., Martin, G., Simm, M., Kotta, I., Herkül, K., Ojaveer, H. Gulf of Riga and Pärnu Bay. In: U. Schiewer (Ed.) Ecology of Baltic Coastal waters. Ecological Studies, 197. Springer-Verlag, Berlin Heidelberg, pp. 217-243, 2008.

[14] Wassmann, P., Tamminen, T. Pelagic eutrophication and sedimentation in the Gulf of Riga: a synthesis. Journal of Marine Systems, 23, pp. 269-283, 1999.

[15] Yurkovskis, A., Poikāne, R. Biogeochemical, physical and anthropogenic transformations in the Daugava River estuary and plume, and the open Gulf of Riga (Baltic Sea) indicated by major and trace elements. Journal of Marine Systems, 70, pp. 77-96, 2008.

[16] Olli, K., Clarke, A., Danielsson, Å., Aigars, J., Conley, D.J., Tamminen, T. Diatom stratigraphy and long-term dissolved silica concentrations in the Baltic Sea. Journal of Marine Systems, 73, pp. 284-299, 2008.

[17] Rönnberg, C., Bonsdorff, E. Baltic Sea eutrophication: area-specific ecological consequences. Hydrobiologia, 514, pp. 227-241, 2004.

[18] Kotta, J., Simm, M., Kotta, I., Kanošina, I., Kallaste, K., Raid, T. Factors controlling long-term changes of the eutrophicated ecosystem of Pärnu Bay, Gulf of Riga. Hydrobiologia, 514, pp. 259-268, 2004.

[19] Herkül, K., Kotta, J., Kotta, I., Orav-Kotta, H. Effects of physical disturbance, isolation and key macrozoobenthic species on community 
development, recolonisation and sedimentation processes. Oceanologia, 48S, pp. 267-282, 2006.

[20] Kotta, J., Lauringson, V., Kotta, I. Response of zoobenthic communities to changing eutrophication in the northern Baltic Sea. Hydrobiologia, 580, pp. 97-108, 2007.

[21] Kotta, J., Paalme, T., Martin, G., Mäkinen, A. Major changes in macroalgae community composition affect the food and habitat preference of Idotea baltica. International Review of Hydrobiology, 85, pp. 693-701, 2000 .

[22] Kotta, J., Kotta, I., Simm, M., Põllupüü, M. Separate and interactive effects of eutrophication and climate variables on the ecosystem elements of the Gulf of Riga. Estuarine, Coastal and Shelf Science, 84, pp. 509-18, 2009.

[23] Clarke, K.R., Gorley R.N. Primer v6. User Manual/Tutorial. Primer-E, Plymouth, 192 p., 2006.

[24] BACC. Assessment of Climate Change for the Baltic Sea Basin. Regional Climate Studies, 22, Springer, 474 p., 2008.

[25] Kautsky, H., Martin, G., Mäkinen, A., Borgiel, M., Vahteri, P., Rissanen, J. Structure of phytobenthic and associated animal communities in the Gulf of Riga. Hydrobiologia, 393, pp. 191-200, 1999.

[26] Cederwall, H., Jemakovs, V., Lagzdins, G., Long-term changes in the soft-bottom macrofauna of the Gulf of Riga. ICES Journal of Marine Research, 56S, pp. 41-48, 1999.

[27] Kotta, J., Kotta, I. Viitasalo, I. Effect of diffuse and point source nutrient supply on the low diverse macrozoobenthic communities of the northern Baltic Sea. Boreal Environmental Research, 5, pp. 235-242, 2000.

[28] Miller, N. Environmental politics. Rutledge, NY, 207 p., 2009.

[29] Anon. Regulatory vs. academic science. Center for Science and Technology Policy Research, University of Colorado. http://sciencepolicy.colorado.edu/klamathbasin/science_policy/regulatory _vs_academic.html 